\title{
Microstructural and Fractographic Characterization of a Thermally Embrittled Nuclear Grade Steel: Part I - Annealing
}

\author{
José R. Tarpani*, Maria H.P. Braz, Waldek W. Bose Filho and Dirceu Spinelli \\ Engineering School of São Carlos, University of São Paulo, \\ Av. Trabalhador São-Carlense 400, 13566-590 São Carlos - SP, Brazil
}

Received: September 27, 2001; Revised: July 10, 2002

\begin{abstract}
A nuclear reactor pressure vessel steel was submitted to different annealing heat treatments aimed at simulating neutron irradiation damage. The obtained microstructures were mechanically tested with subsequent metallographic and fractographic characterization. The relevant microstructural and fractographic aspects were employed in the interpretation of the mechanical behavior of the microstructures in both quasi-static (J-R curve) and dynamic (Charpy impact) loading regimes. A well defined relationship was determined between the elastic-plastic fracture toughness parameter J-integral and the Charpy impact energy for very most of the microstructures.
\end{abstract}

Keywords: fractography, fracture toughness, microstructure, pressure vessel steel

\section{Introduction}

The manipulation of structural materials in the as-irradiated state is a costly, time consuming and hazardous activity. The simulation of neutron damage inducing changes on the mechanical behavior of alloy steels through heat treatment is a recent technology ${ }^{1-4}$ towards the development of laboratory testing methodologies for the nuclear industry, as well as to hydrotesting of prototype and full-scale pressure vessels. In Part I of this work, a nuclear grade steel is submitted to seven different annealing heat treatments, aimed at obtaining a variety of elastic-plastic fracture toughness in both the quasi-static (J-R curve) and dynamic (Charpy impact) regimes. The relevant microstructural and fractographic aspects exhibited by the materials are employed in the interpretation of their mechanical behaviors in both quasi-static and dynamic loading conditions. On these bases, the feasibility of simulating neutron damage through heat treatments is then assessed. In Part $\mathrm{II}^{5}$, additional quenched and tempered (Q\&T) microstructures are evaluated in the same way as the annealed materials.

\section{Material}

The Brazilian ASTM A508 Class 3A steel is a typical reactor pressure vessel material for the nuclear industry. The deliberately thermally embrittled microstructures of this steel (chemical composition in Table I), were obtained through annealing heat treatments by using different soaking times and temperatures. The result was a broad microstructure spectrum, exhibiting a wide range of fracture toughness systematically inferior to the material in the original condition. Figure 1(a) shows the thermal cycle applied to the steel for the as-delivered condition (original microstructure named A), including the simulated post-welding heat treatment (PWHT). Figure 1b shows the resultant microstructure, composed of a ferritic matrix (light areas), with finely dispersed granular carbides (dark areas), rendering to it the nomination of granular or globular bainite ${ }^{6}$. This singlephase microstructure presented an average grain diameter of $19 \mu \mathrm{m}$ (8.5 micrograin ASTM number).

\section{Experimental}

\section{Heat Treatment}

The embrittling thermal cycles applied to the A508 steel are presented in Fig. 2. The resultant microstructures, nomi-

Table I. Chemical composition of the A508-3A steel; wt $\%$.

\begin{tabular}{ccccccccc}
\hline $\mathrm{C}$ & $\mathrm{Si}$ & $\mathrm{Mn}$ & $\mathrm{Ni}$ & $\mathrm{Mo}$ & $\mathrm{Cr}$ & $\mathrm{Al}$ & $\mathrm{P}$ & $\mathrm{S}$ \\
\hline 0.19 & 0.24 & 1.30 & 0.72 & 0.51 & 0.03 & 0.012 & 0.007 & 0.009 \\
\hline
\end{tabular}

*e-mail: jrpan@sc.usp.br 

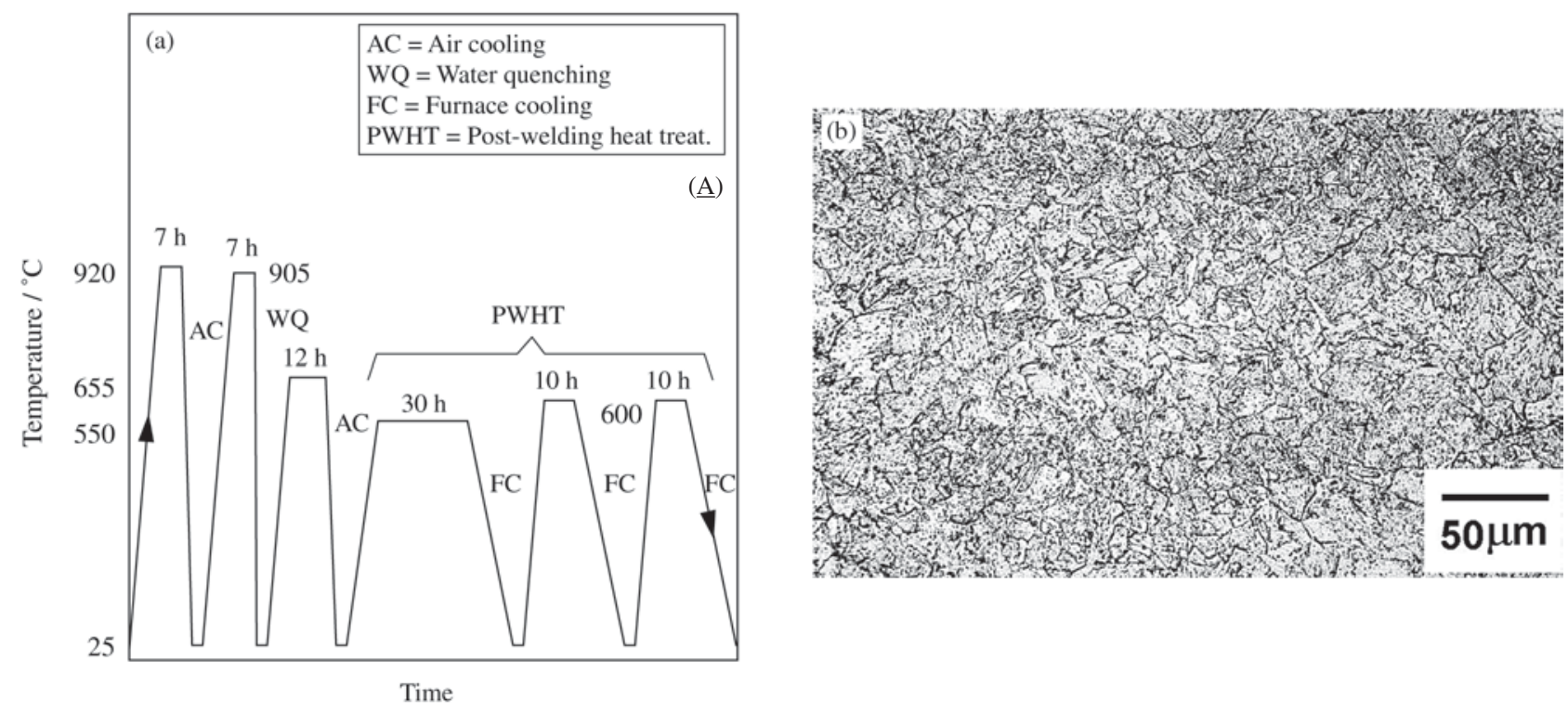

Figure 1. a) Original thermal cycle; b) A508 steel in the as-received condition (A). Etching: Nital $2 \%$.

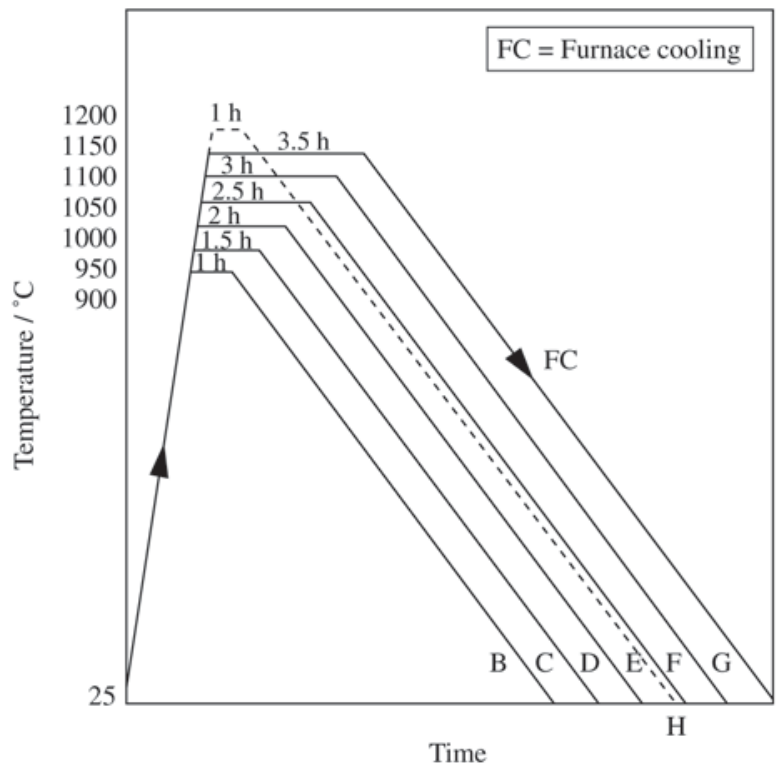

Figure 2. Thermal cycles corresponding to the seven annealing heat treatments, B-H.

nated $\mathrm{B}-\mathrm{H}$, were evaluated along with the original microstructure, $\mathrm{A}$.

\section{Quasi-static and Dynamic Fracture Toughness}

J-R curve testing ${ }^{7}$ were carried out at $300{ }^{\circ} \mathrm{C}$ through the elastic compliance technique, using miniaturized compact tensile specimens, $5 \mathrm{~mm}$ and $10 \mathrm{~mm}$-thick ${ }^{8}$. They were fatigue precracked to a nominal $0.5 a_{0} / \mathrm{W}$ ratio, where $a_{0}$ is the initial crack length and $\mathrm{W}$ is the specimen width, and side-grooved to $33 \%$ of their gross thickness, $\mathrm{B}_{\mathrm{G}}$. From the $\mathrm{J}-\mathrm{R}$ traces, the rate of increase on the J-material's cracking resistance, $\mathrm{d} / \mathrm{d} \Delta a_{(1 \mathrm{~mm})}$, was derived for a $1 \mathrm{~mm}$ of crack growth, $\Delta a^{8}$.

Type-A bend bar Charpy testpieces ${ }^{9}$ were prepared similarly to J-specimens. They were impacted at $300{ }^{\circ} \mathrm{C}$ in an instrumented testing machine using a 300 Joules hammer travelling at a speed of $5.5 \mathrm{~m} / \mathrm{s}$. The absorbed energy was digitally recorded, which accounted for energy losses due to friction, windage and specimen tossing, i.e. the net absorbed energy was obtained. The impact energy was then tentatively correlated to the parameter $\mathrm{dJ} / \mathrm{d} \Delta a_{(1 \mathrm{~mm})}$ above described.

\section{Metallography and Fractography}

The average grain diameters and phase percentage of the embrittled microstructures were determined using a computerized image analyzer. The fracture surface survey was performed in a scanning electronic microscope equipped with a probe, for chemical microanalysis.

\section{Results}

\section{Metallography}

It can be noticed in Fig. 3 that the microstructures obtained from the annealing heat treatments contain two distinct phases, comprising a mixture of nearly equiaxial ferritic grains (light areas) and globular low carbon bainite (dark areas). Bainite gets more refined as the austenitizing time 

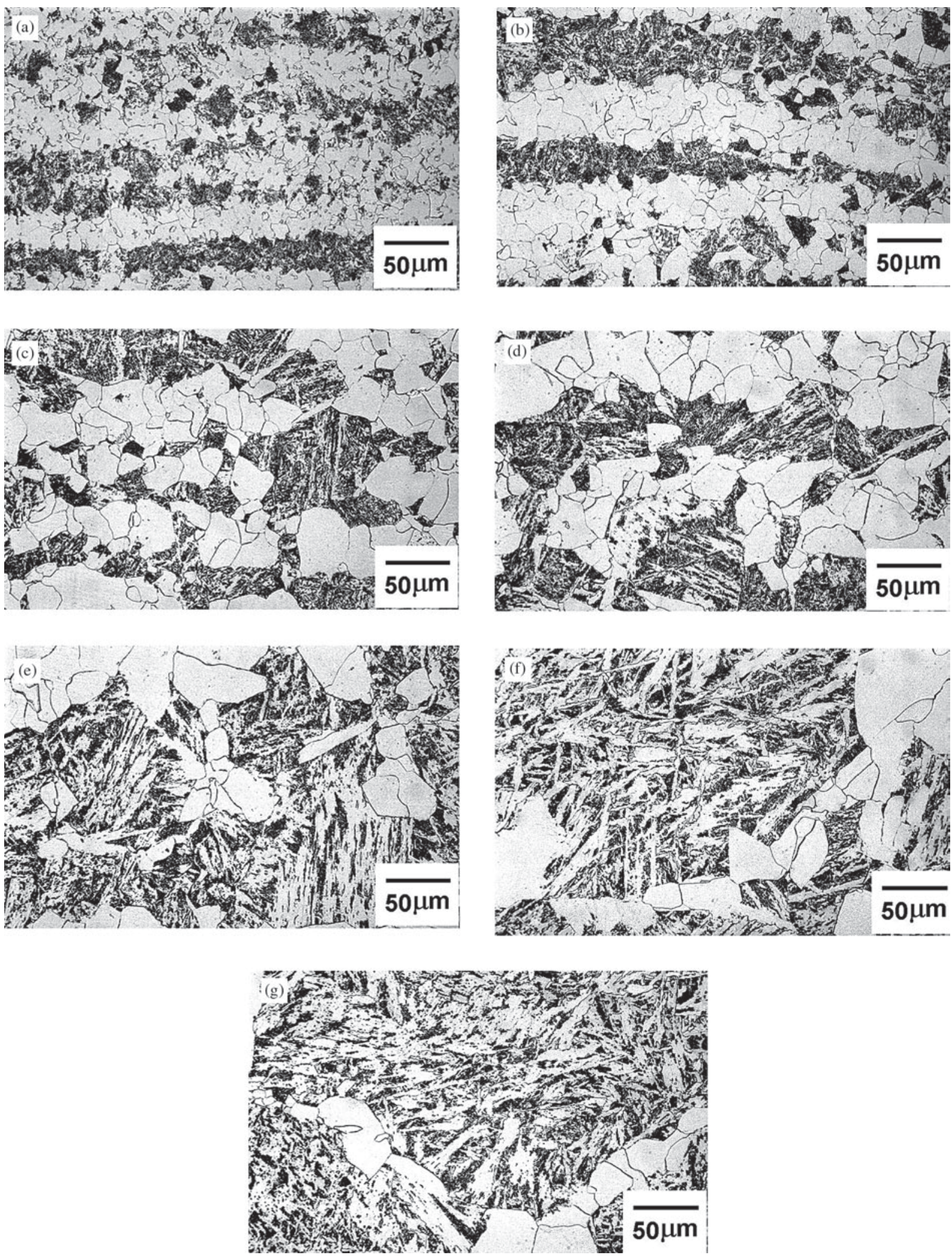

Figure 3. All the embrittled microstructures obtained from individual annealing heat treatments of the A508 steel. a) Thermal cycle B, b) C, c) D, d) E, e) F, f) G and g) H. Etching: Nital $2 \%$. 
and temperature rise simultaneously (except for $\mathrm{H}$ ), as realized by the marked alignment of the carbide particles, i.e, acicularization of the structure as one goes from microstructure $\mathrm{B}$ to $\mathrm{H}$. This microstructural change was brought about by the increase of the hardenability of the annealed microstructures, as promoted by the increasing austenite grain size. The $\mathrm{B}$ and $\mathrm{C}$ microstructures, Figs. $3 \mathrm{a}$ and $3 \mathrm{~b}$, are quite banded in the hot-work (forging) direction, but banding is relieved as the annealing become more severe (from B to $\mathrm{H})$. The $\mathrm{H}$ and, in less extent, the $\mathrm{G}$ microstructure, Figs. $3 \mathrm{~g}$ and $3 \mathrm{f}$, are constituted of large grains of refined bainite, surrounded by ferritic grains grown along the prior austenite grain boundaries. It can be noted that ferrite exhibits a modest average grain size compared to bainite, but a larger grain size distribution than the latter.

Table II shows that, as expected, both ferritic and bainitic grains grow rapidly with the annealing severity. Comparing $\mathrm{G}$ to the $\mathrm{H}$ microstructure, Figs. $3 \mathrm{f}$ e $3 \mathrm{~g}$, it can be concluded that the effect of the austenitizing temperature on the final grain sizes is much more pronounced than the soaking time at that temperature. It can be seen, from $\mathrm{B}$ to $\mathrm{F}$ microstructures, Figs. 3a to 3e, that the proportion between the phases ferrite/bainite is kept almost constant, of about 1:1. However, for the $\mathrm{G}$ and $\mathrm{H}$ microstrucures, Figs. $3 \mathrm{f}$ and $3 \mathrm{~g}$, it can be noticed a striking increase in the bainitic grain size with austenitizing temperature and, in a much less extent, in the ferritic grain dimension. This corroborates the overwhelming effect of both austenitizing time and temperature, notably on these high temperatures levels here established, on the grain growth rate. Under these conditions, it can be realized as well the increase of the volume occupied by the bainite phase at expenses of the proeutectoid ferrite. This allows one to infer the remarkable effect of the prior austenite grain size in rising the hardenability of the alloy during its phase transformation, thus preventing the pro-eutectoid ferritic phase from being generated.

Table II. Ferritic and bainitic average grain diameters, and percentage of both phases in the thermally embrittled microstructures. ASTM micrograin size number is provided in brackets.

\begin{tabular}{cccc}
\hline $\begin{array}{c}\text { Annealing Heat } \\
\text { Treatment }\end{array}$ & $\begin{array}{c}\mathrm{D}_{\text {ferrite }} \\
(\mu \mathrm{m})\end{array}$ & $\begin{array}{c}\mathrm{D}_{\text {bainite }} \\
(\mu \mathrm{m})\end{array}$ & $\begin{array}{c}\% \text { Phase } \\
\text { ferrite/bainite }\end{array}$ \\
\hline B & $20(8.3)$ & $19(8.5)$ & $48 / 52$ \\
C & $30(7.2)$ & $26(7.6)$ & $49 / 51$ \\
D & $39(6.4)$ & $50(5.7)$ & $50 / 50$ \\
E & $47(5.9)$ & $56(5.4)$ & $50 / 50$ \\
F & $50(5.7)$ & $64(5.0)$ & $51 / 49$ \\
G & $55(5.4)$ & $475(0)$ & $19 / 81$ \\
H & $61(5.1)$ & $817(00)$ & $11 / 89$ \\
\hline
\end{tabular}

\section{Fractography}

As seen in Fig. 4b, the microstructure B presents a fracture surface with fully ductile aspect developed by nucleation, growth and coalescence of microvoids under quasistatic loading conditions. It can be noticed that the dimples size distribution is quite narrow, $100 \mu \mathrm{m}$ maximum estimated diameter. Only few and spaced second phase particles, $30 \mu \mathrm{m}$ maximum diameter, identified as silicates, aluminates and sulfides, are noted. The steel is absent of clusters of inclusions, reflecting its high cleanliness. In general, inclusion shape was slightly deformed, denoting the relatively low strain rates imposed during thermo-mechanical forging of the original $130 \mathrm{~mm}$-thick plate. In the fracture surface referring to the original A microstructure, Fig. 4a, which exhibited maximum fracture toughness, there is predominance of very small microvoids, but a duplextype size distribution is also observed. This indicates the role of both inclusions (large microvoids) and carbides (submicrometric voids), in the fracture process of the A508 steel in the as-received condition. It is well known that carbides need a much higher local deformation, i.e. energy consumption, to nucleate dimples, than that required for inclusions. Therefore, it can be inferred that the maximum fracture toughness presented by the A microstructure, was due to the predominance of microvoids nucleation in carbide particles, as opposite to the microstructures derived from the annealing heat treatments, specially the severer ones. Microvoids, observed in the fracture surface of the original and all annealed microstructures, display an elongated shape oriented in the ductile crack propagation direction. The C-F microstructures, Figs. 4c-4f, which are systematically less tough than A and B, exhibit increasingly larger average dimple size when compared to the latter microstructure. This indicates that nucleation is a more effective energy consumption step than microvoids growth and coalescence during crack propagation. Therefore, it is possible to infer that the average void size growth during the slow crack propagation process is closely and proportionally related to the microstructure grain size, and inversely, to the capacity of the microstructure to spawn microvoids. Secondary cracking perpendicular to the main fracture path is observed in the $\mathrm{E}$ and $\mathrm{F}$ microstructures, Figs. $4 \mathrm{e}$ and $4 \mathrm{f}$, as well as micro regions of mixed fracture mode, which reflect the reduction in toughness of these microstructures, as compared to the $\mathrm{A}$ and $\mathrm{B}$ conditions. The fracture surfaces of the $\mathrm{G}$ and $\mathrm{H}$ microstructures, Figs. $4 \mathrm{~g}$ and $4 \mathrm{~h}$, present a beehive-like aspect, with very shallow dimples, disclosing the low permanent strain ability of these materials along the main loading direction. They, therefore, demand a low energy consumption, although still in the elastic-plastic regime. Thus, it is quite probable that both $\mathrm{G}$ and $\mathrm{H}$ microstructures possess very similar fracture 

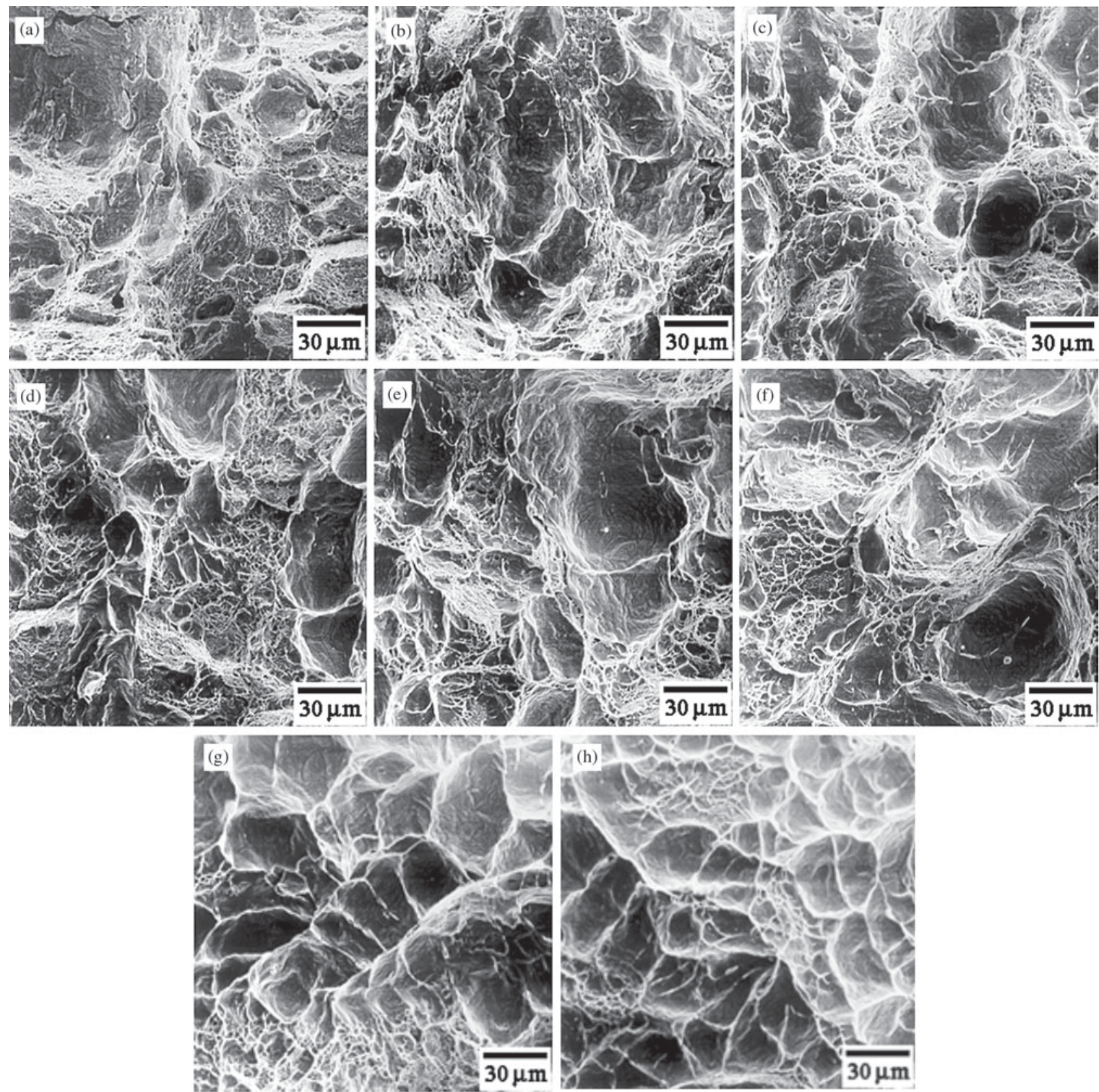

Figure 4. Fracture surface topographies of J-R curve testpieces. a) A508 steel in the as-received condition, A; b) Embrittling thermal cycle $\mathrm{B}, \mathrm{c}) \mathrm{C}, \mathrm{d}) \mathrm{D}, \mathrm{e}) \mathrm{E}, \mathrm{f}) \mathrm{F}, \mathrm{g}$ ) $\mathrm{G}$ and $\mathrm{h}$ ) $\mathrm{H}$. Crack growth direction is from the bottom to the top of the page.

toughness.

It is clearly noticed from Fig. 5, that the dynamic fracture surfaces exhibit a more planar aspect (shallower dimples) when compared to quasi-static loading condition, though fracture mode was, likewise, transgranular and essentially ductile. From B microstructure, Fig. 5b, it is observed the development of micro regions that could be clas- sified as mixed mode fracture mechanism. As the annealing time and temperature are risen, from $\mathrm{C}$ to $\mathrm{F}$ microstructures, Figs. $5 \mathrm{c}$ to $5 \mathrm{f}$, a significant percentage of the fracture area is occupied by this dual-mode mechanism. It is observed from A to F microstructures, Figs. 5a to 5f, that a highly localized rupture by shear mode was developed, as a secondary fracture mechanism in paralle planes to the crack 

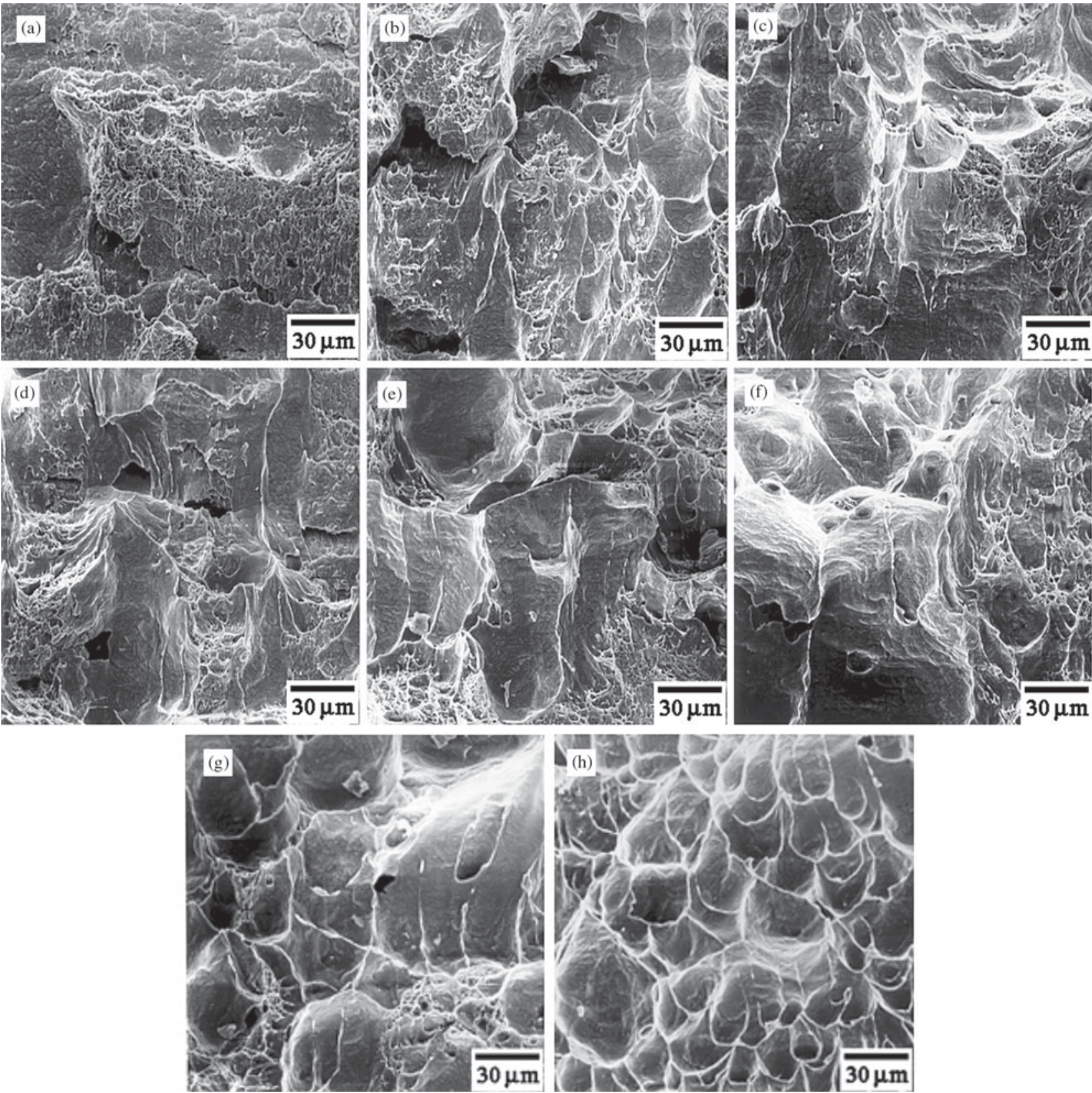

Figure 5. Fracture surface morphologies of dynamically loaded Charpy testpieces. a) A508 steel in the as-received condition, A; b) Embrittling thermal cycle B, c) C, d) D, e) E, f) F, g) G and h) H.

propagation. As a consequence, dimples are highly strained towards crack advance direction.

The fracture surfaces generated under dynamic loading in the $\mathrm{G}$ and $\mathrm{H}$ microstructures, Figs. $5 \mathrm{~g}$ and $5 \mathrm{~h}$, shows up once more, the honeycomb pattern, with an extremely shallow but still ductile aspect. Indeed, the $\mathrm{H}$ microstructure seems to be slightly more ductile than G. In general, under both static and dynamic loading all the microstructures present fractographic characteristics that obey the same chronological sequence, specially related to microvoids size and depth, that brings up the increasing level of microstructural embrittlement achieved by heat treatment.

\section{Fracture Toughness Correlation}

Microstructural and fractographic analyses suggest that quasi-static and dynamic fracture toughness parameters may 
sustain a close correlation between them. Figure 6 shows a good correlation between the quasi-static fracture toughness parameter $\mathrm{d} J / \mathrm{d} \Delta a_{(1 \mathrm{~mm})}$, and the Charpy impact energy, considering three different $\mathrm{J}-\mathrm{R}$ curve fitting methods. It is worthy of note that, inasmuch as J-integral testing of asirradiated materials is complex, costly, hazardous and time consuming, there has been a strong and natural interest in establishing trusty correlation between elasto-plastic J-integral criteria and those derived from simpler, cheaper, safer and faster test methodologies, as Charpy impact testing ${ }^{10,11}$.

Still in Fig. 6, although A is basically a quenched and tempered microstructure, it correlates well with the annealed ones, as denoted by the high values attained for the correlation coefficients (R). This unexpected behavior can be possibly due to the heavy tempering treatments applied to it during the PWHT simulation, which probably rendered to A some microstructural similarities to the annealing microstructures. In general, the induced embrittlement for increasingly severe annealing heat treatments equally reflects in both, quasi-static and dynamic mechanical behaviors. This may indicate the existence of a Hall-Petch ${ }^{12,13}$ type relationship connecting them and the grain size of the annealed microstructures. However, it was not possible to identify the reason why the D microstructure exhibited a distinct behavior from that expected, grounded on its average grain sizes. This indicates that another variable, possibly related to the trade-off between grain growth and microstructure

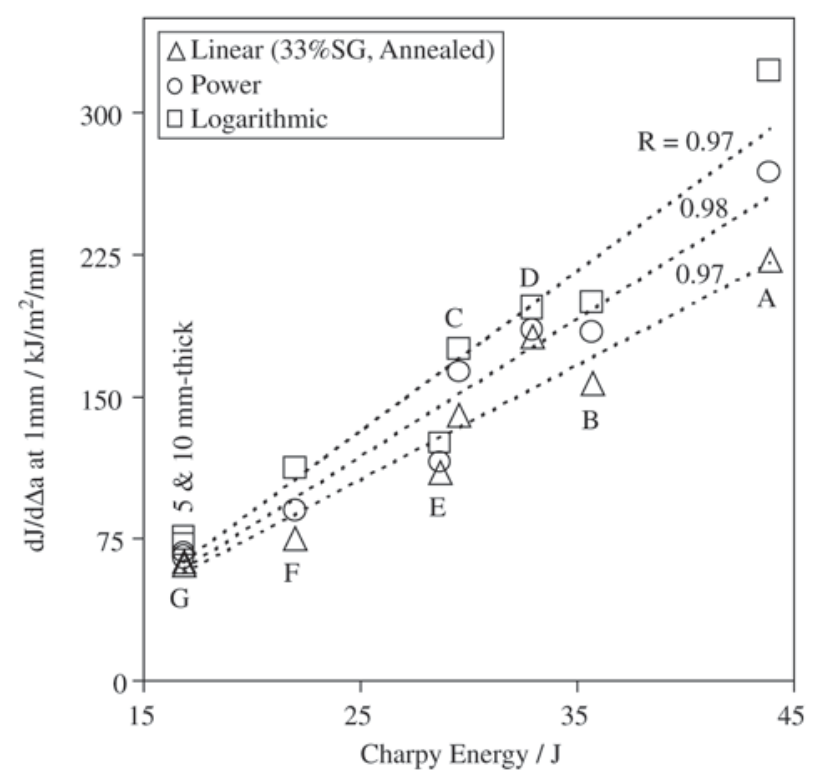

Figure 6. Correlation between quasi-static (J-integral) and dynamic (Charpy) fracture toughness parameters. J-R testpieces are $10 \mathrm{~mm}$ thick otherwise stated. (bainite) refinement, as mentioned earlier, plays a major role in the fracture mechanics behavior of this microstructure, besides the well known grain size effect.

Correlations between grain size and elastic-plastic fracture toughness parameters are proposed in literature ${ }^{14,15}$, only for single-phase metallic materials, invariably on the basis of the widely accepted Hall-Petch relationship, which originally established that the yield strength varies inversely to the square root of the grain size. The results so far obtained in the present study for dual-phase microstructures, show that, besides the average grain size of both phases, it must be considered an extra variable, certainly related to the individual contribution of each phase to the overall fracture toughness of the alloy, thus resembling the rule of mixtures of composite materials. In this sense, studies are in progress seeking for the quantification of these partial contributions, by determining the preferential crack path through the microstructures during both, static and dynamic loading conditions. This could provide subsides to the proposition of a general rule that would allow the inference of the mechanical behavior of this class of steel, based exclusively on the microstructural particularities, maybe in the form of an equivalent, i.e. representative grain size.

Regarding the $\mathrm{H}$ microstructure, it was not possible to determine the value of the $\mathrm{dJ} / \mathrm{d} \Delta \mathrm{a}(1 \mathrm{~mm})$ parameter, due to the large scatter in the J-R curve data. In Fig. 6, referring to the $\mathrm{G}$ microstructure, it can be noticed that the $\mathrm{dJ} / \mathrm{d} \Delta a_{(1 \mathrm{~mm})}$ figures from both 5 and $10 \mathrm{~mm}$-thick J-testpieces are in close agreement, thus indicating a testpiece size independence, with regard to quasi-static fracture toughness. This fact is particularly important for the fracture mechanics community, as long as the specimen size independence would afford the structural integrity assessment of massive structures by simply testing small-scale testpieces in lab environments.

\section{Concluding Remarks}

This study has shown the feasibility of obtaining a broad range of fracture toughness from a nuclear reactor pressure vessel steel, through annealing heat treatments, in order to simulate the mechanical performance, viz. the fracture toughness, of in-service neutron exposed structural metallic alloys. It has been also demonstrated the existence of a well defined linear correlation between the quasi-static and dynamic fracture toughness parameters obtained from $\mathrm{J}$ integral and Charpy impact testing, respectively. Both facts may lead to considerable simplification, cost and time savings, as well as risk reduction in periodic inspection programs, laboratory testing and hydrotesting of pressurized water reactor vessels and related components. Further, it has been shown the possibility to develop Hall-Petch type relationships by establishing links between the quasi-static 
and dynamic fracture toughness and the equivalent or representative grain size of dual-phase annealed microstructures.

\section{Acknowledgements}

The authors gratefully acknowledge the financial support provided by FAPESP - Fundação para o Amparo à Pesquisa do Estado de São Paulo (Contracts 97/05652-1 and 99/09431-5) and CNPq - Conselho Nacional de Pesquisa e Desenvolvimento (140789/2000-6).

\section{References}

1. Onizawa, K. et al. Int. J. Press. Vessel Piping, v. 70, p. 201-207, 1997.

2. Pokrovsky, V.V. et al. Int. J. Press. Vessel Piping, v. 54, p. 9-24, 1994.

3. Vatter, I.A. Int. J. Press. Vessel Piping, v. 54, p. 31-48, 1993.

4. Vitale, E.; Beghini, M. Int. J. Press. Vessel \& Piping, v.
46, p. 289-338, 1991.

5. Tarpani, J.R. Part II submitted to Materials Research, 2002.

6. Bramfitt, L.B.; Speer, J.G. Metall. Trans., v. 21A, p. 817829, 1990.

7. Standard Test Method for Measurement of Fracture Toughness, ASTM Handbook, 1996.

8. Hackett, E.M.; Joyce, J.A. Nuclear Engng Design, v. 134, p. 217-226, 1992.

9. Standard Test Methods for Notched Bar Impact Testing of Metallic Materials, ASTM Handbook, 1996.

10. Wallin, K. Fatig. Fract. Eng. Mater. Struct., v. 24, p. 537-549, 2001.

11. Gioielli, P.C. et al. ASTM STP (Special Technical Publication) v. 1360, p. 61-68, 2000.

12. Petch, N.J. J. Iron Steel Inst., v. 174, p. 25-32, 1953.

13. Hall, E.O. Proc. Phys. Soc. B., v. 64, p. 747-753, 1951.

14. Srinivas, M. et al. Acta Metall. Mater., v. 39, p. 807816, 1991.

15. Srinivas, M. et al. Eng. Fract. Mech., v. 28, p. 561-576, 1987. 